\title{
A literatura de autoajuda e a Produção de SUBJETIVIDADE FEMININA
}

http://dx.doi.org/10.1590/1984-0292/1318

\author{
Gisele Mocci (Haya Del Bel)I, ${ }^{I}$, Guilherme Augusto Souza PradoII \\ ${ }^{I}$ Universidade Federal de Mato Grosso, Cuiabá, MT, Brasil \\ ${ }^{I I}$ Universidade Federal Fluminense, Niterói, RJ, Brasil
}

\section{RESUMO}

Neste artigo visamos uma análise crítica das condições de subjetivação oferecidas a partir da literatura de autoajuda da virada do século. Propomos seis categorias a fim de evidenciar o ideal identitário propagado nos textos alocando-os segundo o que é sua suposta essência, papéis sociais e valores. Apoiados nos estudos de Lasch e Giddens, percebemos que esta identidade feminina essencial, reitera o lugar de subjugação da mulher na sociedade ocidental. Seguindo pistas de Guattari e Rolnik, propomos uma concepção de subjetividade aquém da identidade e da essência individual ou de gênero, como atualização de forças de afetação e desejo.

Palavras-chave: literatura de autoajuda; identidade feminina; subjetividade.

\section{Self-help Literature AND THE PRODUCTION OF FEMALE SUBJECTIVITY}

\begin{abstract}
This article makes a critical analysis of the conditions of the subjective production offered by self-help literature in the end of XX century. We propose six categories in order to demonstrate the identitary ideals propagated in the texts, as they antagonize sexes, we allocate them according to what is supposed to be its essence, social papers and values. Supported in Lasch's and Giddens'studies, we realize that this essential feminine identity, reiterates women's subjugation in western society. Following Guattari and Rolnik's clues, we propose a conception of subjectivity that precides identity and individual essence or gender formations, as an upgrading of affection and desire forces.
\end{abstract}

Keywords: self-help literature; female identity; subjectivity.

\footnotetext{
^Endereço para correspondência: Universidade Federal de Mato Grosso, Instituto de Saúde Coletiva. Fernando Correia da Costa, 2367 - Boa Esperança. 78060-900 - Cuiabá, MT - Brasil. E-mail: hayadelbel@gmail.com, izzyitba@gmail.com
} 
Desde a segunda metade do século XX a literatura de autoajuda passa por um processo crescente de vendas. No Brasil há, pelo menos, duas décadas e meia, está entre os livros mais vendidos nas livrarias. Apesar de não ser exclusivamente direcionada à mulher, a maioria de seus títulos direcionam a leitura prioritariamente a esse público.

Tais publicações visam não somente atender, como paralelamente criam e reforçam a demanda de orientação, em nível de comportamentos e valores, para a vida das mulheres, oferecendo um repertório de respostas às questões existenciais e cotidianas. Assim, a literatura de autoajuda tem se constituído como um dos principais instrumentos de identificação e de reprodução dos diversos sistemas de significação pelo sujeito contemporâneo.

Em meio à perda dos referenciais ordenadores da vida, ao sentimento de solidão e à sensação de desorientação, investigamos como incide a atual crise de identidade sobre as mulheres, tendo em vista sua inserção no espaço público e a conquista de novos papeis sociais. Isto significa que ao lado dos papeis sociais definidos historicamente para o gênero feminino (a maioria deles relacionado ao espaço privado do lar e da família), surgem outros, que exigem das mulheres a interação com um sistema de valores e comportamentos até então estranho a elas.

Os autores de autoajuda partem da constatação de um conflito entre os sexos, e o localiza no desconhecimento da determinação e fixação dos papeis de cada um dos gêneros.

Nós, por outro lado, partimos do pressuposto de que não há essência ou verdade fundamental do sujeito, de forma que este atravessa a vida em processos de identificação e construção de si mesmo segundo os diversos sistemas significantes dados ou construídos na dinâmica de semiotização do mundo.

Desta maneira, questionamos o perfil de mulher oferecido pela literatura de autoajuda. Especificamente, interpelamos o universo de referência constituído a partir dos processos de identificação de individuação e de subjetivação que sustentam este estrito perfil, assim como a imagem de feminilidade essencial que a autoajuda produz, promove e enaltece. Interrogamos os traços e valores que norteiam a produção de subjetividade, as normas e os comportamentos para as mulheres.

Destacamos um modelo de mulher abstraído a partir da leitura desses livros, atentando ao ideal em cada um dos autores e o que se pode concluir de uma análise comparativa entre seus discursos. Associamos tais discursos, os sistemas de produção e de veiculação de imagens peculiares ao contexto de surgimento e circulação dos livros.

Responder as perguntas propostas nesta investigação exige um cruzamento de dois temas de estudos: o tema das condições de vida contemporâneas, com Lasch (1983) e Giddens (1993), e a identidade feminina engendrada na literatura de autoajuda. Para tanto, nos valemos privilegiadamente dos escritos de Guattari e Rolnik, acerca da constituição ontológica do ser mediante os processos de subjetivação e de individuação. 
Selecionamos quatro obras da literatura de autoajuda ${ }^{1}$ que propõem diferenças de papeis entre homens e mulheres e estabelecem um sistema de traços femininos definido a partir da oposição com o masculino. Esses autores sugerem uma identidade feminina concebida dentro de um esquema dicotômico de valores e de comportamentos.

Os títulos são: Por que os homens fazem sexo e as mulheres fazem amor? (PEASE, A.; PEASE, B., 2000) e Por que os homens mentem e as mulheres choram? (PEASE, A.; PEASE, B., 2003); Homens são de Marte, mulheres são de Vênus (GRAY, 1995); e Homem cobra, Mulher polvo (TIBA, 2004).

As obras do corpus analisado se prestam a orientar os leitores a prover melhorias no relacionamento com o sexo oposto. Para tanto, os autores partem do pressuposto de que os conflitos que comprometem a harmonia das relações devem-se às diferenças peculiares e intrínsecas aos dois sexos, ao desconhecimento ou esquecimento da essência de cada um e, consequentemente, de seu horizonte de ação e de percepção.

Entretanto, as orientações dadas pelos quatro autores em seus livros de autoajuda dizem respeito a questões não apenas individuais e coletivas, antes incidem no ponto onde ambas se implicam em incursões e interfaces entre desejo e ordem social que formam o sujeito.

Nos textos de autoajuda o indivíduo é apresentado a priori, como se existisse uma essência humana intrínseca que se manteve intacta e alheia ao processo histórico de formação dos indivíduos em sociedade. Discordando deste raciocínio, argumentamos que a individuação e a subjetivação, ou o processo de tornar-se indivíduo e sujeito, é necessariamente coletivo, contíguo à história e à política. Definitivamente, não há um ser ou essência do que vem a ser homem ou mulher. Antes, é o tipo de produção de subjetividade de nossa cultura - modo capitalístico, projetado na realidade do mundo e na realidade psíquica segundo Guattari e Rolnik (2005) - que tende a individualizar os processos subjetivos, forjando um paradigma identitário de subjetividade interiorizada e serializada suscetível à manipulação pelos equipamentos capitalísticos.

\section{IDENTIDADE E CONSTITUIÇÃO DO SUJEITO}

A construção da identidade individual no século XX tem sido extensamente discutida nas teorias sociais. Entre os autores que debatem o tema, Christopher Lasch (1993) aponta que com o esvaziamento do discurso coletivo e das práticas na esfera pública, resta ao indivíduo contemporâneo o investimento no próprio eu, geralmente voltando-se para o substrato biológico do eu e a busca de uma essência. Seja através das diversas formas de terapia de aprimoramento do eu (a busca em tornar-se "uma pessoa melhor"), seja através das academias de ginástica, cursos de formação continuada e reciclagem, religiosidades (que, desde que tomada de maneira light, adquire um uso cosmético, que não compromete o indivíduo a 
postulados ético-teleológicos), yoga, e uma longa lista de implementos para a subjetividade na qual podemos incluir sem problemas o fenômeno da literatura de autoajuda como dispositivo capitalístico de individuação em massa.

Tal configuração é apenas aparentemente permissiva, pois subjaz nela um sistema de controle, mais efetivo na medida em que evita confrontos diretos acerca de princípios. Sob esta configuração é que se instaura a política subjetiva da autoajuda, a qual remete ao discurso da autoridade para postular uma concepção de essência biologizante, desbaratada dos meandros políticos e sociais das formações subjetivas, que são datadas. Cada forma de subjetivação sofre interferências de variados campos de força e, no entanto, o discurso da autoajuda prefere aludir a um modo de subjetivação essencial e intrínseco a cada sexo apoiando-se para tanto na ratificação de dispositivos científicos de saber.

As afirmações aparecem de um lugar de autoridade, que Lasch (1983) define como ordem sancionada pela força. Portanto, se a literatura de autoajuda lança mão do recurso à autoridade é para dispor e impor um ordenamento aos desejos e aos indivíduos, é para forjar regimes de constituição subjetiva, é no intuito de determinar as formas de individuação a partir de um lugar privilegiado, de um posicionamento instaurado a partir de relações de poder.

Tendo isto em vista, nos interrogamos acerca da identidade forjada a partir do enquadramento nas categorias de definição do espaço existencial da mulher na literatura de autoajuda. De antemão, podemos antecipar que o discurso da autoajuda tem como centro um emaranhado de conclusões tiradas de um número de deduções científicas não aleatórias que retomam e reificam a colocação sociopolítica da mulher na sociedade patriarcal. Para tanto, exploramos as nuanças e modelizações da subjetividade feminina a partir de seis categorias construídas na leitura dos textos de autoajuda para então traçar um perfil das representações indentitárias forjadas para a mulher. Vale assinalar a especificidade do entendimento de semiótica que tratamos neste espaço. Trata-se daquilo que Guattari (1993) denomina processos semióticos e semiotizantes que podemos distender em três elementos: a produção um tipo de narrativa ou de uma forma de narrar, a proposição de um sistema de valoração e seus desdobramentos em regimes estritos de práticas. Ou seja, a semiótica estabelece um olhar e propõe uma forma, reproduzida ou inventada, de viver.

Distinguimos, portanto, este sistema, que constitui um repertório dos fenômenos de expressão, de uma concepção de semiótica que podemos chamar de tradicional, sob uma perspectiva leitura saussureana, como um subúrbio da linguística (GUATTARI; ROLNIK, 2005). As semióticas não se restringem à tradução, à passagem de um código a outro, como delimitam o campo do que é visto, sentido, vivenciado e feito. Agindo como uma estrutura ou um modo estruturante da percepção, como um campo de intensidades que, modulado de acordo com um regime de signos, se inscreve no tempo e no espaço a partir de relações sociais, formações inconscientes, ecológicas, corporais, icônicas, linguísticas, técnico-científicas, religiosas, estéticas dentre tantas outras. 
Desta maneira, a semiótica não fica tão à parte do sentido e da realidade, pois coloca a produção material, subjetiva e semiótica num plano coemergente e complementar. Trata-se de um sistema semiótico, cuja eficácia está nas formas como e muda uma realidade assim como, por outro lado, nas maneiras em que uma realidade adquire efeito semiotizante engendrando uma variedade dos modos de semiotização.

Neste sentido, um regime de signos constitui uma semiótica e há uma multiplicidade de regimes de signos, que se explica pela diversidade das formas de expressão. Logo, o que chamamos de semióticas abrangem todo e qualquer sistema, mais ou menos fechado, de significação capaz de instaurar padrões e colocar em funcionamento maquinários de orientação social e cósmico.

Não obstante, os modos de semiotizar realidades, os distintos modos de significação, podem se articular entre si. As semióticas são montadas e construídas, por vezes gerando novidades semiotizantes, noutras se valendo de modelos existentes ou de elementos e traços destes modelos. Elas tornam as coisas discerníveis, engendrando, mais que permitindo, discernibilidades e transparências. Este sistema de codificação - produzido ou imposto, a um indivíduo ou a um grupo - permite ao indivíduo, atravessado pelos processos de semiotização em curso nele e a seu redor, crer no seu "eu”, bancar sua identidade a ponto de confundir a ruína desta com seu próprio dilaceramento. Neste âmbito, a literatura de autoajuda funciona como um meio de comunicação, que fala para os indivíduos e por eles, funcionando como um "muro de linguagem que propõe ininterruptamente, modelos de imagens nas quais o receptor possa se conformar" (GUATTARI; ROLNIK, 2005, p. 58)

Destarte, não somente tomamos o discurso da autoajuda como uma semiótica - que geralmente estabelece um corte com sua dimensão política e com sua finitude -, mas como um polo de entrecruzamento entre varias semióticas dominantes, pois os modos de semiotização dominante pesam sobre determinada realidade política.

Assim sendo, dentre uma diversidade das formas de semiotização possíveis, a modelização da subjetividade em voga em nossa sociedade capitalística separa os universos semióticos da produção subjetiva. Tornando estes processos exteriores e impermeáveis um ao outro, a semiótica capitalística pretende instituir regras de equivalência geral constante abrangentemente, produzindo enunciados de equivalência e significação do que incute ser uma mulher, por exemplo. Desta forma é que, no entrecruzamento de um nicho de semióticas, a literatura de autoajuda hierarquiza atividades e valores, determinando o campo do visível, assim como as possibilidades de ação e os mecanismos das práticas determinando as maneiras com que encaixamos as ações, comportamentos, valorações e atividades no mundo. 


\section{Categorias de análise}

\section{1 - Sexualidade, namoro e casamento}

No amor e na sexualidade apresenta-se a dicotomia básica que separa as condutas masculina e feminina: a atividade e o movimento são atitudes próprias do homem como a passividade e a inércia o são da mulher.

Em uma frase de John Gray (1995), a oposição entre conquistador e conquistada se faz com mais sutileza, reforçando a concepção de um macho ativo e de uma fêmea passiva na esfera do amor e do erotismo humano. Lembrando sempre que uma mulher precisa sentir-se amada e que o homem precisa alimentála com seu amor para que ela permaneça constante em seu sentimento, o autor profere: "Quando um homem ama uma mulher, ela começa a brilhar com amor e satisfação" (GRAY, 1995, p. 126). Repare-se, pela construção da frase, como se dá, no discurso deste autor, a relação de cada sexo com a experiência do amor e ascendência do homem sobre a mulher.

Esta diferença na experiência amorosa se traduz, no texto de Içami Tiba, numa atitude masculina de controle, ao colocar a mulher sob seu território, e uma atitude feminina de cuidado: "a polvo se excita só de sentir quanto é desejada pelo cobra. A expressão do seu amor é ter o homem sempre consigo, nos seus braços, nutri-lo, agasalhá-lo, acariciá-lo, beijá-lo e dizer muitas e muitas vezes quanto o ama" (TIBA, 2004, p. 17).

Dessa forma, o homem busca, no amor, controlar, sobrepor-se ao outro, ao passo que a mulher quer subsumir-se em proveito do parceiro masculino. No amor, é próprio do sujeito masculino afirmar-se e do feminino negar-se. Içami Tiba (2004, p. 15-16) traduz esta oposição da seguinte forma: "A expressão máxima do amor do cobra é possuir a sua fêmea. [...] A expressão máxima do amor da polvo é cuidar do seu homem e dar-lhe muitos filhos". Para a mulher, portanto, o amor é vivido como doação de si ao outro, por isso ela se realizaria no cuidado do homem e na vivência da maternidade, isto é, no cuidado da prole.

Depois de identificarem, amor e sexo, Pease, A. e Pease, B. seguem separando-os para esclarecer as diferenças de gêneros no relacionamento erótico. Oposição, aliás, explícita no título de um de seus livros, que sugere que o homem valoriza mais o sexo, enquanto o amor é mais apreciado pelas mulheres. Os autores são, aqui, categóricos em reificar traços culturais que vinculam a subjetividade masculina a sexo e buscam legitimação deste discurso em bases científicas: "homem quer sexo, mulher quer amor. Disso já se sabe há milhares de anos, mas raramente se fala sobre o assunto" (PEASE, A.; PEASE, B., 2000, p. 187). Eles identificam no cérebro duas regiões distintas para o amor e para o sexo (o hipotálamo), sendo que no cérebro masculino, cada região tem ação independente uma da outra, enquanto no cérebro feminino ambas se comunicam. O que leva a conclusão de que o homem se satisfaz com "um relacionamento baseado em forte atração física", mas a mulher precisa que a região do amor seja estimulada para que o hipotálamo funcione (PEASE, A.; PEASE, B., 2000, p. 210). Não obstante, a região do amor corresponde às habilidades para converter o 
ato físico em imagens e signos: "Para a mulher, fazer uma declaração de amor não é o problema. Sua estrutura cerebral enche seu mundo de sentimentos, emoções, comunicação e palavras" (PEASE, A.; PEASE, B., 2000, p. 208).

Aqui, a nulidade do sujeito feminino assegura-lhe um prazer dissociado do orgasmo, pois o que vale é sentir que o parceiro a deseja. Como a mulher é um receptáculo vazio de sentimentos, necessidades ou vontades, o prazer da mulher aparece condicionado ao desejo do homem; é ele, com sua índole ativa e conquistadora, que pode conferir o amor e o prazer à parceira apenas com a intensidade do seu desejo: "para a mulher, mesmo que a transa seja boa, dificilmente ocorre o orgasmo. Sentir-se desejada pelos homens é muito gratificante. Sentir que realiza o desejo do seu querido não é o mesmo que um orgasmo, mas chega perto, bem pertinho [...]" (TIBA, 2004, p. 24-25).

Se o homem procura o sexo para se aliviar de problemas, como o desemprego, as dívidas e outros fatores diários de estresse, a mulher se inibe diante do ato sexual em situações semelhantes (PEASE, A.; PEASE, B., 2000, p. 171). O homem age e a mulher recolhe-se, ela não pode desejar quando envolvida com dificuldades do dia-a-dia enquanto ele deve estar sempre pronto para o coito.

Percebemos, nas descrições dos autores analisados, que o desejo é remetido a uma essência do que vem a ser mulher e o desejo feminino, de um lado, e do que vem a ser homem e seu desejo masculino, de outro. Desta forma, o sujeito só pode desejar, mais do que a biologia de seu sexo permite, o que vem a ser possível a seu grupo identitário sexual desejar. Neste ponto, os autores são categóricos: "os valores e as prioridades da mulher moderna são os mesmos que há séculos fazem parte do mundo feminino, ainda que vividos de forma diferente" (PEASE, A.; PEASE, B., 2000, p. 228). Eles são porta-vozes da tirania biológica e identitária que afirma o que cada um deve querer para sua vida, confinando e essencializando o desejo, como neste trecho: "as prioridades sexuais de homens e mulheres são tão opostas que não faz sentido ficarem se castigando. Não há nada há fazer, eles são como são" (PEASE, A.; PEASE, B., 2000, p. 189).

\section{2 - Afetividade}

Conforme os textos analisados, cada um dos sexos têm um campo tipificado de ação e percepção próprio, diferença perceptível, para Gray, em situações de crise, tensão ou dificuldade. A descrição do autor para o comportamento de um homem diante de uma dificuldade que o leva ao aborrecimento é o silêncio diante do incômodo, sendo impossível partilhar daquilo que ocasiona este aborrecimento (GRAY, 1995, p. 41).

Compare-se com esta descrição de uma mulher na mesma situação: "Quando uma venusiana fica aborrecida ou estressada com o seu dia, para encontrar alívio, ela procura por alguém em quem confie e então conversa com todos os detalhes sobre o problema do seu dia". (GRAY, 1995, p. 41). O autor coloca o que chama de competência como algo fora da alçada da mulher, mais envolvida em sistemas sentimentais e na partilha de sentimentos como o de fragilidade de confusão de cansaço e de desesperança. 
Depreende-se, destes dois trechos, que um homem não expõe seus sentimentos por vergonha de que eles denunciem uma fragilidade ou incompetência que não pode admitir, ao contrário da mulher, aparentemente imune a essa insegurança com relação a suas próprias fraquezas. A mulher, sob pressão, toma por uma "bênção" a oportunidade de uma conversa com o parceiro, a qual é um incômodo para o homem; textualmente, uma "interferência em seu processo de resolução de problemas” (PEASE, A.; PEASE, B., 2000, p. 124).

Enquanto a introspecção masculina é recolhimento para concentração no objeto que o incita e no problema que o estimula, a expansividade feminina é a expressão de um pensamento subjetivo - nada objetivo -, voltado para a reação do sujeito ao problema. Por um lado, o homem se retrai para se concentrar nos problemas, por outro, "as mulheres se tornam progressivamente indefesas e emocionalmente envolvidas. [...] Ele se sente melhor resolvendo problemas, enquanto ela se sente melhor conversando sobre problemas" (GRAY, 1995, p. 40).

Com o uso do par de verbos resolver/conversar, a observação do autor opõe uma vontade de ação masculina à inércia feminina. O homem está, portanto, todo voltado à ação e seus sentimentos não conhecem outra realidade senão a do mundo exterior dos objetos e dos fenômenos. Se ele não consegue resolver o problema que o perturba, busca um desafio em outra esfera, onde pode agir em vez de permanecer inerte à espera de uma solução passiva.

Essa "objetividade" peculiar ao homem se estende também a seu vocabulário, numa fala mais concisa e precisa do que a feminina:

\begin{abstract}
[...] os homens usam frases curtas, diretas, que se encaminham para uma solução, um desfecho. Empregam um vocabulário mais amplo e enriquecem com fatos o que dizem. Os termos são bem definidos, como 'nenhum', 'nunca' e 'absolutamente' (PEASE, A.; PEASE, B., 2000, p. 95).
\end{abstract}

Pease, A. e Pease, B. remetem ao passado pré-histórico da humanidade e à atividade de caça para explicar a inaptidão masculina para o manejo e a expressão dos sentimentos, que converge numa maior objetividade. Seguindo este raciocínio, o homem não pode manifestar qualquer emoção que possa ser entendida como fraqueza tampouco entender empaticamente outros seres, porque precisa lutar contra eles e vencê-los, ao contrário da mulher que, desincumbida dessa tarefa truculenta, desenvolve mais sua sensibilidade.

\title{
3 - Maternidade, paternidade e educação dos filhos
}

$\mathrm{Na}$ opinião dos quatro autores analisados, Pease, A. e Pease, B., Gray e Tiba, muito desta dinâmica amorosa e sexual é determinada, pelo imperativo biológico de reprodução para preservação da espécie. Tendência que se mantém quanto a maternidade, a paternidade e a educação dos filhos.

De uma forma geral, podemos depreender que o destino da mulheré assegurar a preservação da espécie oferecendo seu corpo e sua existência à procriação e ao cuidado da prole; no homem, o cuidado consigo antecede a atividade paterna. A 
paternidade é um atributo de segundo plano no projeto masculino, pois a ele - mas não à mulher! - a natureza confere um instinto de sobrevivência que o leva a lutar por uma integridade física e moral pessoal; mas a mulher, desprovida de uma atenção "instintiva" para consigo própria, vive para o coletivo e a espécie.

Para o homem, o instinto de autopreservação e o sexo são primeiros em relação à paternidade, enquanto para a mulher-polvo, "os filhos estão acima de tudo em qualquer momento. Para o cobra, que está no escritório, o trabalho vem em primeiro lugar" (TIBA, 2004, p. 47). Logo, questiona o autor "tem coisa mais importante para a mãe do que dar de comer aos filhos?" (TIBA, 2004, p. 56).

Pease, A. e Pease, B. citam uma pesquisa para demonstrar como a maternidade está no destino da mulher. Em uma entrevista com 5.000 mulheres norte-americanas, apenas $1 \%$ colocou o sexo como prioridade em sua vida pessoal, contra $80 \%$ que aponta a maternidade como critério de autorrealização. Ignorando todo sistema de normatização social e captura da produção desejante incutido na questão, os autores rapidamente deduzem: "moral da história: a maternidade ainda é o que mais satisfaz as mulheres" (PEASE, A.; PEASE, B., 2000 , p. 228). Conclusão que aparece irrefutável pois, além de estar, durante milhares de anos, cuidando e alimentando os filhos enquanto o marido persegue, primeiro a caça, depois uma bola de futebol (PEASE, A.; PEASE, B., 2003, p. 127), a mulher é "vítima" da progesterona, o hormônio do "instinto maternal e protetor", que assegura the assegura que cumpra "com eficiência seu papel de guardiã da cria” (PEASE, A.; PEASE, B., 2000, p. 139).

\section{4 - Cognição}

Condiçõese formas distintas de afetação, de sentire serelacionar, desdobramse em maneiras diferentes de intelecção e processamento de informação para os dois sexos. $\mathrm{O}$ talento feminino estaria no conhecimento emocional e intuitivo dos objetos e seres circundantes, para atingir dois imperativos biológicos: a defesa do espaço doméstico e a comunicação com a prole: "a mulher precisa ter capacidade de olhar para a sua ninhada e identificar imediatamente a dor, o medo, a fome, a doença, a tristeza e a alegria" (PEASE, A.; PEASE, B., 2003, p. 177), avaliando ambientes e elementos amistosos ou agressivos.

Em contraposição a este esquema perceptivo e de ação mais sentimental, o homem "tem objetivo determinado e prazo certo" (PEASE, A.; PEASE, B., 2000, p. 130). Ele se aborrece com um passeio ao shopping, enquanto para a mulher isso surge como "uma atividade lúdica" (PEASE, A.; PEASE, B., 2000, p. 130). Os autores pretendem ainda explicar, com o mesmo argumento, a lendária curiosidade feminina: "não se trata de que as mulheres sejam curiosas... bem, elas não deixam de ser [...] é que com a sobrevivência a longo prazo programada em seus cérebros, elas querem saber como vai cada pessoa de seu grupo e como podem ajudar" (PEASE, A.; PEASE, B., 2003, p. 166). 
Pela mesma razão, segundo Içami Tiba (2004, p. 36), elas gostam tanto de novela: "novela e polvo foram feitas uma para a outra". A afinidade da mulher com a novela deve-se, antes, aos temas sentimentais que encontraram eco na peculiar atividade cognitiva do cérebro feminino. É que o homem quer entender e a mulher, apenas sentir.

Há momentos em que a habilidade de concentração masculina parece uma limitação: "Andar, conversar e controlar a bexiga são atividades demais para o cérebro do homem-cobra realizar ao mesmo tempo", indica Içami Tiba (TIBA, 2004, p. 39). Logo, porém a desigualdade operacional é transladada para a moral e reconvertida em valor positivo para o homem. Pois em vez de aplicar seu talento e habilidade tentacular para tarefas múltiplas, com objetivos racionais e elevados, esta característica feminina é entendida como uma propensão a enganar. "Quando a polvo quer, consegue coisas do cobra que ele nem sonha, enquanto o cobra dificilmente consegue enganar uma mulher. Afinal, o cobra é uma limitação da polvo, só tem um tentáculo" (TIBA, 2004, p. 83). Da mesma maneira, Pease, A. e Pease, B., tomam o que se conhece por "intuição feminina" por uma "apurada capacidade que a mulher tem de notar detalhes e alterações mínimas na aparência e no comportamento de outras pessoas" (PEASE, A.; PEASE, B., 2000, p. 26).

\section{5 - Sociabilidade}

A partir dos estudos das obras, observamos que mulheres e homens apresentam diferentes valores que determinam sua concepção de vida em comunidade assim como o desempenho de sua vida social. Um dos capítulos do livro PEASE, A.; PEASE, B., 2000, intitula-se Por que os homens são agressivos?, denotando, nos termos, um pressuposto de que a agressividade é peculiar e intrínseca ao sexo masculino.

Na origem desse antagonismo comportamental entre os sexos está a oposição - milenarmente anunciada e atualizada no discurso dos autores abordados - entre a competição masculina e a integração feminina. Em um jogo ou uma disputa, essa diferença, segundo os autores, torna-se evidente: "Nenhum cobra disputa um campeonato porque 'o que vale é competir'. [...] Se ele entra, é para ganhar. [...] Para a polvo, é preferível compor a competir” (TIBA, 2004, p. 55).

Diferença também resumida em uma fórmula de Pease, A. e Pease, B.: "Meninas buscam relacionamento e cooperação. Meninos buscam poder e status" (PEASE, A.; PEASE, B., 2000, p. 120). Os autores citam exemplos de situações em que crianças distinguem-se nas reações conforme o sexo. Quando, por exemplo, estranhos chegam ao grupo, são recebidos diferentemente por meninos e meninas: "as meninas aceitam melhor quem chega e são mais solidárias com coleguinhas deficientes. Os meninos com frequência desprezam ou implicam com os mais fracos" (PEASE, A.; PEASE, B., 2000, p. 121).

A maior habilidade feminina para a integração soma-se a um peculiar talento para a comunicação e a linguagem. Pease, A. e Pease, B. (2003, p. 176 e 177) afirmam que exames de ressonância magnética revelam que a presença de pontos responsáveis pela decodificação de palavras e sinais corporais e de 
voz é de uma a duas vezes maior no cérebro feminino do que no masculino. Por outro lado, o hormônio feminino estrogênio é apontado como o catalisador desses processos de codificação nas células cerebrais (PEASE, A.; PEASE, B., 2000, p. 59). Não obstante, as mulheres apresentam um repertório de comunicação verbal, sons vocais e signos paralinguísticos entre os sexos, discrepantemente maior que os homens (PEASE, A.; PEASE, B., 2000, p. 86).

\section{6 - Trabalho}

Nas obras consultadas, as diferenças de ocupação do espaço de trabalho por mulheres e homens foi extraída a partir de alguns excertos e indicações esparsos.

O casal Pease usa a história para argumentar esta "verdade" biológica: "se estudarmos a História, vamos ver que praticamente nenhuma mulher se destacou em áreas que exigem habilidade espacial e raciocínio matemático como o xadrez, engenharia espacial, ou composição musical" (PEASE, A.; PEASE, B., 2000, p. 112). Para eles, isso prova que as mulheres não possuem talento inato para estas tarefas, dada sua menor capacidade para atividades que exijam concentração lógica. Os autores concluem, por outro lado, que, no campo profissional, o modo de falar feminino "seria desastroso", já que desenvolve um raciocínio "sinuoso e indireto". Por isso, "no mundo dos negócios, para impressionar a ala masculina, a mulher deve calar seus pensamentos e só falar quando chegar a uma conclusão" (PEASE, A.; PEASE, B., 2000, p. 84).

Na obra posterior, no entanto, os autores estendem esta divisão social do trabalho ao conceberem um espaço público dividido, em que cada um aprende a lidar com as diferenças de cada sexo. Na esfera do trabalho, o homem deve compreender que a mulher primeiro estabelece uma ligação pessoal para então passar aos negócios. "E a mulher precisa entender que o homem se sente desconfortável discutindo assuntos pessoais e por isso prefere passar direto aos negócios" (PEASE, A.; PEASE, B., 2003, p. 51). Desta forma, os autores naturalizam, sob o argumento de um "relacionamento comercial mais consistente", em suma, de uma melhor interação entre os sexos, construções histórico-sociais de gênero, colocando-os sobre uma pretensa perspectiva científico-evolutiva.

Já o livro de Içami Tiba pode oferecer dados para reflexão sobre o trabalho e os gêneros, desta vez, mais pelo que oculta do que pelo que diz. Segundo o autor, a aposentadoria torna o homem ocioso, mas dificilmente tem o mesmo efeito sobre a mulher: "a polvo não se aposenta nunca. Sempre acha o que fazer ou do que falar" (TIBA, 2004, p. 73). Içami Tiba atribui à atividade ininterrupta da mulher uma disposição, ao que parece, natural. Não ocorre ao autor que a falta de uma aposentadoria se deve à impossibilidade da suspensão das tarefas domésticas prioritariamente atribuídas à mulher. Ninguém pode se aposentar do espaço privado, cujos serviços devem prover as necessidades básicas suspensas apenas com a morte. Se o homem cai na ociosidade, não seria justamente por nunca se ocupar das tarefas domésticas? Se a mulher não se aposenta, não significa isso que uma disposição sempre vívida para o trabalho, a patente demonstração de que a atividade feminina no espaço doméstico não é 
reconhecida como trabalho e não se sujeita às leis de uma aposentadoria de fato? As observações de Içami Tiba e dos demais autores levam, portanto, a graves equívocos a respeito da desigualdade entre os sexos.

Pease, A. e Pease, B. (2003, p. 214) não desencorajam a mulher de ocupar o espaço público de trabalho, antes, a aconselham a criar duas personagens, uma para cada espaço: "a mulher moderna tem dois códigos básicos de vestuário: roupa de trabalho e roupa de não-trabalho". O primeiro serve para conferir-lhe posição de igualdade perante os homens do mundo de negócios. Além disso, nesse espaço, os "signos de atração" que ela mantém na conquista amorosa são indesejáveis. Por outro lado, a diferença deve continuar a ser mantida quando se trata do jogo da conquista, onde a hierarquia não dispõe de outros índices - como, por exemplo, um organograma de cargos e funções ou uma tabela salarial - para gerir as relações de poder entre os sujeitos: "as lições a serem aprendidas aqui são claras: a mulher deve usar cabelo comprido quando quer atrair os homens e cabelo curto ou puxado para trás em reuniões de trabalho" (PEASE, A.; PEASE, B., 2003, p. 216).

Os autores (PEASE, A.; PEASE, B., 2000, p. 230) asseguram que a maquiagem virilizante do corpo feminino é indicativa de como o espaço público de trabalho continua a ser considerado um domínio masculino. Por outro lado, sua reificação nas relações privadas de encontro amoroso agencia a preservação da mulher neste espaço como objeto de desejo masculino. Aparentemente o discurso oculta um raciocínio que pode ser ilustrado da seguinte forma: já que nós homens permitimos que vocês mulheres ocupassem vagas que historicamente eram nossas, então é necessário que se comportem como um membro do grupo já estabelecido, ou seja, se comportem como homens.

\section{UMA SEMIÓTICA DE MULHER}

Agrupando percentualmente as categorias temos o seguinte resultado: sexualidade corresponde a $46 \%$ dos temas abordados, afetividade a $18 \%$, trabalho $13 \%$, cognição $11 \%$, maternidade e sociabilidade a $6 \%$ cada uma. Notamos que as orientações acerca da ocupação do espaço público pela mulher é bem menor do que a destinada a ocupação do espaço privado. Se somamos maternidade, afetividade e sexualidade temos um total de $70 \%$ do espaço médio utilizado pelos autores para apresentação dos temas, deixando claro que espaços culturais, sociais, públicos são secundários no aconselhamento e modulação comportamental da mulher.

Tendo isto em vista, podemos tomar certa concepção de mulher e traçar um perfil, oferecido como modelo pela literatura de autoajuda a partir da elucidação dos elementos elencados nas categorias narrativas.

Este perfil é como um tipo de subjetividade prêt-à-porter, que Rolnik (1997) conceitua em Toxicômanos da identidade. Trata-se de uma forma de existir pronta para uso, que ignora as forças constituintes da subjetividade capazes de abalar e desestabilizar a identidade, tomada como um processo de subjetivação a priori. ${ }^{2}$ 
Tal sistema de captura e produção subjetiva deposita os destinos e condições da subjetividade nos kits de perfil-padrão a serem consumidos de acordo com a órbita do mercado, independentemente de contexto geográfico, nacional, cultural, etc. Exatamente como acontece com o perfil de mulher propagado pela autoajuda, identidades locais fixas desaparecem para dar lugar a identidades globalizadas flexíveis que mudam ao sabor dos movimentos do mercado e com igual velocidade.

Mediante isto, interpelamos a semiótica, as grades de leitura e a produção subjetiva que entendem a mulher a partir de um prisma de insatisfação e como falta a ser preenchida. Trata-se da imagem da mulher que se enxerga como reflexo do desejo masculino, conforme assinala Giddens (1993). O desejo desta mulher se orienta mais para ser amada do que para propriamente amar, por isso "necessitam" ser admiradas, apreciadas e valorizadas.

Na produção deste tipo de semiótica, não há escapatória à determinação inata de fundo biológico de uma origem natural dos gêneros e dos sexos, que aplana e banaliza o social. Destarte, a mulher é associada à inércia e à passividade no comportamento sedutor e de receptividade no qual ela aparece como vazio a ser preenchido pelo homem que tem como características a ascendência sob seu território, assim como o controle, a atividade e o movimento, exercidos sobre e em contraposição, à mulher.

Se por um lado o homem tem que acreditar no poder de sua ação, a mulher aprecia a doação de si ao outro; ele precisa sentir a si mesmo na relação amorosa, ela precisa senti-lo. Assim, a mulher sente a variação de humor, vive-a em seu próprio interior e no interior da relação e logo, reage emocionalmente conforme essa intimidade aumenta ou diminui.

Esta atenção aos sentimentos torna-a naturalmente mais comunicativa, capaz de expressar suas emoções, assim como pedir e oferecer ajuda. Em contraponto à introspecção masculina e à capacidade de concentração no objeto, a capacidade de partilha dos problemas confere à mulher uma expansividade, centrada na resposta à reação do sujeito ao problema. Qualidade reconvertida em inação, desvalorizando a comunicação de sentimentos, o que é condensado na assertiva: ela conversa, ele resolve.

Tudo isto não significa somente uma restrição às possibilidades de subjetivação da mulher, mas uma efetiva captura dos afetos e das forças de afecção, dos sujeitos e das formas de subjetivação. Assim, características tipificadas como femininas, tais como a compreensão e a manifestação de emoções sem receio de demonstrar fraqueza, assim como a permanência, a estabilidade e a espera são traduzidas como inércia. E, além disso, são reconvertidas no entendimento de que a mulher vive para o coletivo da família e da espécie. O que ratifica tal entendimento é o fato da mulher ter a maternidade como meta e ser "vítima" da progesterona, o que propicia as características de integração e comunicação, que se opõem à agressividade masculina na competição. 
Não há, nas obras analisadas, uma categoria diretamente referente ao trabalho, o que por si, já pode ser tomado como um analisador. No entanto, a caracterização do perfil de mulher acima descrito já a coloca em segundo plano no campo competitivo do mundo do trabalho. Não obstante, algumas obras exaltam a mulher a se calar no mundo dos negócios, apenas se manifestando a título de conclusão. A lógica de menosprezo do trabalho da mulher não para por aí; para o trabalho privado e doméstico - nas obras, designado à mulher não há descanso ou aposentadoria.

A isto, se soma alguns recursos de agenciamento que disseminam, impregnam e promovem a produção subjetiva em escala industrial, como a facilidade de leitura, que ajuda a literatura de autoajuda a atingir um maior número de leitoras. Ao que se adiciona alguns recursos mais interessantes ainda como indução e condução de pensamento usando de argumentos científicos e a utilização de testes que determinam previamente e restringem o âmbito de respostas possíveis para as questões colocadas, envolvendo o leitor na trama de sua argumentação.

\section{SOBRE A PRODUÇ̃̃o SUBJETIVA}

Logo, problematizamos certas concepções e afirmações arraigadas acerca do perfil de mulher prescrito pela autoajuda. Perfil no qual as forças de transformação da subjetividade são capturadas, fixando papeis e características identitários, os quais são reconvertidos segundo um sistema de valoração que subjuga a mulher seguindo a política sexual dominante.

Aleitura dos textos de autoajuda através das categorias apontadas demonstra a ação de captura e a produção individualizante, dentro dos dispositivos de reprodução social atuais, de certo modo de ser mulher. Seu discurso reduz a mulher a um específico nicho de sensibilidade, colocação e possibilidade existencial ao lhe tolher a dimensão ontológica de transformação do ser, seu vir a ser.

Este perfil de mulher se torna possível segundo a lógica capitalística individualizante, calcada numa axiomática de segregação subjetiva que determina normas sociais, através da coerção material externa e da sugestão de conteúdos de significação. Esta delimitação do campo de possibilidades no domínio psíquico circunscreve o que vem a ser digno para a existência, de maneira a regular a subjetividade de modo mais insidioso que a coerção explícita (PEIXOTO JR., 2004). O devir é capturado ao se tolher a dimensão afetiva da experiência, dimensão de desestabilização e invenção de novos modos de vida.

Segundo Rolnik (1989), a dimensão afetiva é impessoal e corresponde ao efeito de um corpo sobre o outro, pois o afeto é um devir que se dá entre dois corpos podendo arrastar um corpo alhures, levando-o a outros lugares. Assim, os afetos são intensidades que desindividualizam e dessubjetivizam. Funcionam como linhas de fuga atravessando todo o tecido social e abrindo o campo para imprimir na mulher novas inscrições e inventar existências outras que aquela historicamente formada em nossa sociedade e reproduzida no discurso da autoajuda. 
Quando a experiência se abre para a dimensão afetiva, dando expressão a devires e intensidades e esta figura histórica de mulher perde o sentido, novas figuras podem se atualizar numa dimensão transubjetiva. A abertura de outros campos semióticos para a mulher propicia, por exemplo, uma entrada diferente no mercado de trabalho ou postos de comando, aquém da simulação de uma imagem masculina que podemos verificar no uso de ombreiras ou no visual masculinizado de chefes de Estado como Margareth Thatcher, Angela Merkel, Michelle Bachelet e Dilma Roussef.

A androginia é uma resposta tão pobre e ineficaz para a questão das formas históricas de exploração da mulher quanto a supressão da sexualidade, como se abolindo as tensões sexuais pudéssemos acabar com os conflitos entre os sexos (LASCH, 1983).

O repertório de modos de existência já traçados pela mulher não são um lugar último, um ponto final onde a guerra dos sexos convergiria por fim, são configurações mais ou menos estáveis da produção do social na medida em que correspondem a um tipo de ordenação, transcultural (ROLNIK, 1989), que dissemina a forma social da mulher propagada pelo perfil da autoajuda em todo o Ocidente.

Isto acontece porque, mesmo tendo sua dimensão afetiva desestabilizante diminuída, o desejo, suas práticas e discursos, tende a cristalização das formas, tende a naturalizar suas produções e invenções reduzindo o campo dos possíveis. Por um lado, o desejo é produção do real social, por outro, a sociedade é feita de investimentos de desejo, logo, a direção e estratégia destes investimentos constituem sua atualização em uma prática e um discurso - a atualização do desejo em um tipo de sociedade.

A figura social da mulher investida em nossa sociedade, e disseminada no discurso da autoajuda, oferece como melhor caminho subjetivo uma feminilidade carinhosa, amorosa, paciente, dedicada e preocupada, via de regra definida em termos de relação, como esposa, mãe, filha, nora, etc. Para Guattari (1993), a maneira como narramos se impõe como forma de dar expressão a algo, sobre qualquer sistematização ou designação de funções. Destarte, os autores de autoajuda ignoram alguns milhares de anos da história humana e responsabilizam a evolução biológica por todas as diferenças entre os sexos e os papeis desempenhados por homens e mulheres no âmbito individual, grupal e social. Ao passar de uma rudimentar análise dos comportamentos de homens e de mulheres no tempo das cavernas, transpondo-os para o contemporâneo, os autores reificam o ideal romântico capitalístico patriarcal ${ }^{3}$ identificado por Giddens (1993).

A reiteração do espaço privado como próprio à mulher canaliza seu investimento afetivo para os filhos e o lar; o que faz com que Freud (1996), sensível a esta configuração no começo do século XX, afirme que as mulheres pagam um preço muito mais alto que os homens pela moral sexual civilizada de seus tempos. O sistema de base desta ordenação social propõe a linhagem de descendência patriarcal a partir da sucessão das figuras de Deus ao governante e ao pai; de forma a tornar a autoridade deste incontestável. Perante isto, a mulher é

Fractal, Rev. Psicol., v. 26 - n. esp., p. 607-628, 2014 
compreendida a partir da falta e da inação no posto de dona de casa e segundo as características acima elencadas. Uma das formas que corroboram o delineamento desta configuração e a captura dos afetos em seu potencial de transformação é o amor romântico, que define o espaço da mulher e o preenchimento de seu vazio essencial na reclusão ao lar e na dedicação à prole.

Ao explorar as transformações em relação ao sexo, amor e erotismo, Giddens (1993) pondera que amor paixão e amor romântico são coemergentes na modernidade ocidental à forma narrativa pessoal individualizada. $\mathrm{O}$ primeiro como ruptura com os deveres e a rotina da coletividade, o outro sob uma perspectiva sublime, inserido no contexto das virtudes, da autorrealização e das instituições sociais modernas.

Já no final do século XIX, com a separação entre o lar (espaço da mulher), e o trabalho, a crescente importância da relação emocional com os filhos enfraquece a autoridade do homem, deslocando o centro da família da autoridade para a afeição materna, situação incrementada com a diminuição das famílias. A associação da maternidade com a feminilidade enquanto traço fundamental da personalidade reforça o modelo mãe-esposa, que por sua vez reitera a dicotomia das atividades e sentimentos entre os sexos e propicia o desenvolvimento de um amplo terreno de domínio feminino da intimidade em contraposição à esfera pública, dominada pelos homens. Ao passo que a divisão social do trabalho permanece substancialmente intacta, o poder do homem se encontra ameaçado em seu cerne na medida em que depende da cumplicidade, assim como dos préstimos econômicos e emocionais das mulheres.

Giddens (1993) assinala que para as mulheres sonhadoras do século XIX, o amor paixão tem sua maior expressão na literatura romântica, nos seus ideais de recusa e de esperança - arautos do que vem a constituir a frequente insatisfação feminina, apontada pelos autores de autoajuda. Enquanto isso, a realidade do amor romântico as subordina ao espaço privado do lar e da família. No caso dos homens, a tensão entre os dois tipos de amor converge na separação entre o espaço doméstico de respeitabilidade e a sexualidade erótica encontrada em relações externas, com amantes ou prostitutas.

Neste contexto, concentra-se um tipo de subjetivação em massa da mulher, caracterizada como inerte, passiva e faltosa, sua insatisfação somente é aplacada a partir do reflexo do desejo e da completude masculina, e em especial na forma do matrimônio.

O regime de intimidade 4 do amor romântico apresenta um caráter reparador e presume um registro de comunicação psíquica ao nível de preenchimento de vazio, no qual o indivíduo fragmentado pode tornar-se inteiro apoiando-se no outro e idealizando-o. Nesta configuração, o confinamento da mulher determina sua respeitabilidade e o casamento é tido como seu objetivo primário.

Ademais, Lasch (1983) aponta que, mesmo com a transição do modelo familiar patriarcal para o modelo administrativo empresarial e burocrático, a mulher não deixa de ocupar um lugar subalterno em relação ao homem. 
À despeito da liberação do sexo como fim em si mesmo e da emergência da mulher liberal no plano social, o discurso da autoajuda ainda a reposiciona junto às tarefas e lugares sedimentados historicamente.

No debate contemporâneo, podemos inferir, a partir de Lasch (1983), que a insegurança e os desajustes relacionais aumentam à medida que a demanda das mulheres pela satisfação é cada vez mais insistente, pois ao mesmo tempo em que elas se tornam mais sexualmente acessíveis, a emergência de sua vontade aparece como mais ameaçadora aos homens. Se até os anos 1950, a queixa masculina gira em torno da falta de resposta sexual da mulher, hoje, esta resposta é intimidante, ao passo em que põe em questão a capacidade dos homens de satisfazê-la.

Rolnik (1996) aponta que a guerra dos sexos é fruto de um binarismo antagônico de contradição entre personagens identitários baseados em representações que os indivíduos forjam e vestem para si. Mesmo num cenário como o início de século XXI, onde somos invadidos e expostos, coabitados incessantemente por diferenças através da abundância dos meios de comunicação, observamos com nitidez a recaptura das forças de subjetivação na reiteração de figuras representacionais que buscam certa essência da mulher, cujas características são reconvertidas negativamente segundo a política sexual dominante.

Da análise das figuras estabelecidas em torno das categorias extraídas dos livros de autoajuda, emerge uma identidade essencial da mulher a ser preservada ou resgatada (no vocabulário próprio dos autores). Portanto, qualquer desvio desta imagem constitui uma ameaça de desagregação e desintegração e as diferenças entre os sexos se encontram restritas à dinâmica da lógica dominante de reprodução da ordem social.

No sistema proposto pela literatura de autoajuda, não há grau de abertura para a efetivação de forças e de fluxos que se hibridizam em cada vida, estas forças não encontram canais para sua existencialização. Na medida em que se engendram novas diferenças, as subjetividades enrijecem na tentativa de conservar a eternidade de sua identidade, preservar o conforto de ter uma essência que atravessa o tempo e as formações históricas no afã de driblar a finitude de suas formas.

Este enrijecimento perante a incessante dinâmica de atração e de repulsa das forças se manifesta nos âmbitos profissional, familiar, sexual, econômico, político, cultural, informático, etc. enrijecimento que tem como condição a redução da vida à individualidade e ao plano das representações. Na autoajuda, o apelo à cristalização sob o argumento do natural ou do universal, demonstra não um apreço a um entendimento coletivo, mas dinamita as possibilidades de emergência daquilo que é único nas práticas de si e no processo de tornar-se si mesmo. Neste sentido, a inflexibilização perante mudanças sociais tornase um obstáculo ao princípio micropolítico de individuação em torno das intensidades, inibe os agenciamentos que o corpo da mulher pode realizar para além de seu estrito campo de conexões em torno da sexualidade, afetividade, maternidade, cognição, sociabilidade e do trabalho. Ao vivermos nestes campos pré-estruturadados, deixamos de captar os elementos de cada situação para construirmos suas próprias referências.

Fractal, Rev. Psicol., v. 26 - n. esp., p. 607-628, 2014 
Em uma via de mão-dupla, a autoajuda, enquanto instrumento de subjetivação em massa de nossa sociedade, despersonaliza ao mesmo tempo em que propõe um modelo forjado na igualdade abstrata para as mulheres. Ao contrário da identidade, um conceito de referenciação para existência, a subjetividade é engendrada e modelada no registro social. Logo, a subjetividade individual é derivada de um entrecruzamento de determinações coletivas da vários âmbitos.

Portanto, o indivíduo serializado está na encruzilhada de múltiplos componentes da subjetividade, ele é o resultado de uma produção em massa, que consome formas subjetivas erepresentacionais que nada têm de naturais e universais. Antes, isso ocorre à medida em que o indivíduo, se assujeita, submetendo-se à subjetividade tal qual a recebe, sem se reapropriar de seus elementos.

Neste sentido, a droga oferecida pela literatura de autoajuda denega a desestabilização da figura de mulher propagada no perfil oferecido pelo discurso da autoajuda. Com a insistência num discurso de essência, os vacúolos de sentido tornam-se insuportáveis e são vividos como esvaziamento da própria subjetividade e não de uma de suas possíveis configurações finitas. No intuito de se proteger destes efeitos desestabilizantes e da proliferação das forças que abalam a ilusão identitária, neutraliza-se a tensão entre imagens representacionais constituídas e sedimentadas e as forças de subjetivação, anulando o poder disruptivo e criador desta tensão.

O movimento de forças e fluxos subjacentes aos papeis representados desestabilizam modos de existência e engendram novos modos de existir. A lógica da multiplicidade e dos devires produzem e assediam o plano das formas cristalizadas o qual, reduzido ao campo das formas e representações, torna-se insensível às forças de transformação.

\section{CONTRA A IDEIA DE IDENTIDADE}

Em seu artigo sobre Guerra dos gêneros e guerra aos gêneros, Rolnik (1996) pondera que a perpetuação e o reforçamento da identidade essencial de gênero atua contra a dinâmica da vida, enquanto processo de produção de diferenças. Assim, o combate à própria instituição de gêneros é empreendido a favor da vida e suas misturas. Pois dar corpo e efetivação à mestiçagem e à hibridização das forças e dos fluxos em jogo acarreta na estratégia de subjetivação contrária à dos textos de autoajuda averiguados e implica certo grau de abertura e fluidez ao se afetar pelas forças e improvisar com as novas configurações que se produzem a partir daí.

Entendemos que os atributos de gênero não servem tão somente de limite para vida e para o comportamento, devem servir para dar expansão, mobilidade e plasticidade à mulher. Multiplicar seu horizonte vivencial para que se possa experimentar novas formas de ser mulher e não para se ater a uma determinação do que é apresentado como universal, da idade das pedras até o contemporâneo século XXI. Portanto, nos dispomos a acompanhar 
paisagens psicossociais juntamente ao desmanchamento e ruína de mundos, à perda de sentido, junto à formação de novos mundos, enquanto expressão de afetos contemporâneos e não de universais obsoletos.

Logo, ao propor uma identidade essencial à mulher, que recaptura os afetos e reconverte as possíveis formas de expressão, de percepção e de existência feminina dentro do próprio sistema proposto, a literatura de autoajuda paralisa o movimento de fluxos e de forças de transformação, impedindo que estas encontrem formas de efetuação em meio a princípios sempre em mutação (ROLNIK, 1997). Em contraposição, a potencialização e a ampliação do alcance do desejo propiciam novos tipos de produção social e de criação de mundos, necessários à passagem e à efetivação das intensidades geradas nos encontros aleatórios vivenciados no cotidiano.

Acompanhar as intensidades que percorrem o corpo no momento dos encontros incute apreender o movimento entre as representações e os fluxos de intensidades. Pois o fluxo escapa ao campo da ordenação e desestabiliza o plano das representações, que tem como função estancar os fluxos, canalizar as intensidades e dar sentido a elas. Esta desorientação e reorientação de afetos promove a criação e a transição para outros mundos, outras formas de viver, transformando a produção do social contiguamente às formas como o sujeito se inventa.

Por fim, questionar o sistema de subjetivação do perfil identitário traçado pela literatura de autoajuda coloca em jogo as possibilidades de transformação social para além da política dominante sexual de segregação e de subjugação feminina no ponto em que todas estas questões - de desejo, sexualidade, amor, trabalho, cognição e sociabilidade - se entrecruzam. 


\section{Notas}

${ }^{1}$ A seleção do corpus da literatura de autoajuda para análise foi feita observando-se primeiramente os seguintes critérios: 1- O tema da obra: Foram selecionados livros que, por sua intenção direta de aconselhar na relação homem-mulher, operam substancialmente com um sistema de diferenças sexuais e de gênero; 2- A data de publicação: O corpus da análise limitou-se aos títulos publicados entre 1995 e 2005, ou seja, no intervalo que marca a virada do século; 3- A circulação: Reduziu-se o universo de pesquisa aos livros escritos ou traduzidos na língua portuguesa e difundidos pelo território brasileiro. 4- O posicionamento no ranking de público: Foram avaliados os títulos de maior circulação e possível influência junto ao público feminino.

${ }^{2} \mathrm{~A}$ dinâmica do jogo entre as forças e as formas que estabelecemos a partir de Guattari e Rolnik (2005) se desdobra em todo texto na medida em que a literatura de autoajuda pretende subsumir toda relação entre forças numa forma que se pretende universal e total. O discurso da autoajuda alameja a captura das forças desejantes para aplacar a tensão entre formas e forças que atravessa os diferentes domínios da subjetivação.

As forças subjazem ao processo secundário de constituição corporal individual e são aquilo que dá consistência ao próprio processo de formação e modelização do indivíduo. Processo ligado ao emaranhado de forças coletivas e sociais, que colocam o desejo em questão, desarraigando o indivíduo dos sistemas semióticos aos quais ele se encontra atrelado. O indivíduo não está no princípio deste processo, não é algo colocado de antemão, como lugar de onde emana a produção subjetiva, esta se dá a partir de inúmeros linhas de força que atravessam os indivíduos, podendo vir a se constituir como forma de consistência e de propagação. Guattari e Rolnik (2005) utilizam a figura do indivíduo como um terminal informático que consome subjetividades, sistemas de representação e de regimes de sensibilidades.

Desta maneira, o indivíduo passa a existir em relação à forças, se relacionando com o campo de forças e não como algo em si. O que tomamos como forma, distinta e individuada, não deixa de expressar um campo contínuo de forças, uma paisagem dinâmica cuja impressão de fixidez e é apenas mais uma face das forças desejantes que estão na base do processo de constituição e de naturalização das formações subjetivas.

O campo das forças corresponde a uma dimensão coletiva e impessoal, as formas correspondem à captura e qualificação dos emaranhados de linhas e vetores de forças que nos atravessam enquanto indivíduo, grupo ou socialmente. Cujas transformações abarcam o âmbito infrapessoal, pessoal e interpessoal.

${ }^{3}$ Em sua análise, Giddens (1993) aponta uma série de transformações colocadas em funcionamento a partir da noção de amor romântico. Esta noção introduz a idéia de trajetória e de história individual, que se torna história partilhada de acordo com certo entendimento acerca dos relacionamentos entre gêneros produzido no século XIX. Trata-se afinal de uma história individual que se desdobra na alocação e determinação de lugares e atitudes aceitáveis e (re)produzíveis para cada sexo em nossa sociedade.

Instantaneamente ligado à liberdade e à autorrealização, o amor romântico associa amor ao casamento e à maternidade como destino único e certeiro dos relacionamentos amorosos para a mulher. Não obstante, ele é como uma ratoeira, que coloca em cena a divisão do trabalho e do lar, crivando as fronteiras do espaço público e do privado. Isto se dá na medida em que ele se assenta e se acentua numa divisão social do trabalho entre os gêneros, na qual é delegado ao homem o trabalho remunerado enquanto cabe à mulher as incumbências domésticas.

Em última instância, o amor romântico arregimenta o confinamento da sexualidade feminina, em seus múltiplos âmbitos, na noção de "mulher respeitável", na idealização da figura da mãe, e com a restrição e constrangimento impostos às manifestações da sexualidade feminina.

Neste contexto, porém, em que a virtude passa a designar não apenas inocência da dama, mas algo de especial da pessoa amada, capaz de defini-la e distingui-la, a mulher pode adquirir poder tão somente mediante as alcunhas de mulher-esposa ou mulher-mãe. Afinal, desenha-se uma situação que mantém os homens à distância do reino da intimidade ao mesmo tempo em que se ressalta o casamento como objetivo primário à mulher.

${ }^{4}$ Importante ressaltar que Giddens (1993) considera a intimidade em termos de comunicação emocional, consigo ou com os outros, em parâmetros de igualdade interpessoal. 


\section{REFERÊNCIAS}

FREUD, S. Moral sexual "civilizada" e doença nervosa moderna. In: SALOMÃO, J. (Org.). Obras Psicológicas Completas de Sigmund Freud. Rio de Janeiro: Imago, 1996. Edição Standard Brasileira, v. 11, p. 169-186.

GIDDENS, A. A Transformação da intimidade: sexualidade, amor e erotismo nas sociedades modernas. São Paulo: UNESP, 1993.

GRAY, J. Homens são de Marte, mulheres são de Vênus: um guia prático para melhorar a comunicação e conseguir o que você quer nos relacionamentos. Rio de Janeiro: Rocco, 1995.

GUATTARI, F. Guattari na PUC. Cadernos de Subjetividade, São Paulo, v. 1, n. 1, p. 9-28, 1993.

GUATTARI, F.; ROLNIK, S. Micropolítica: cartografias do desejo. Petrópolis: Vozes, 2005.

LASCH, C. A Cultura do Narcisismo. Rio de Janeiro: Imago, 1983.

PEASE, A.; PEASE, B. Por que os homens fazem sexo e as mulheres fazem amor? Uma visão científica (e bem- humorada) de nossas diferenças. Rio de Janeiro: Sextante, 2000.

PEASE, A.; PEASE, B. Por que os homens mentem e as mulheres choram? Rio de Janeiro: Sextante, 2003.

PEIXOTO JR., C. A. Sujeição e singularidade nos processos de subjetivação. Ágora, Rio de Janeiro, v. 7, n.1, p. 23-38, jan. 2004.

ROLNIK, S. Cartografia sentimental: transformações contemporâneas do desejo. São Paulo: Estação Liberdade, 1989.

ROLNIK, S. Guerra dos gêneros e guerra aos gêneros. São Paulo: Núcleo de Estudos e Pesquisas da Subjetividade da Pós-Graduação de Psicologia Clínica, PUC/SP, 1996.

ROLNIK, S. Toxicômanos de identidade: subjetividade em tempo de globalização. In: LINS, D. (Org.). Cultura e subjetividade: saberes nômades. Campinas, SP: Papirus, 1997. p. 19-24.

TIBA, I. Homem-cobra, Mulher-polvo: entenda as diferenças e seja muito mais feliz. São Paulo: Gente, 2004.

Recebido em: 02 de julho de 2014 Aceito em: 03 de setembro de 2014 